\title{
LÍMITES DEL DERECHO DE AUTOR EN FAVOR DE PERSONAS CON DISCAPACIDAD VISUAL
}

\author{
Isabel Espín Alba \\ Titular de Derecho Civil \\ Universidad de Santiago de Compostela \\ E-mail: isabel.espin@usc.es
}

\begin{abstract}
RESUMEN: La construcción jurídica del derecho de autor se asienta sobre el equilibrio entre los intereses de los titulares de derechos exclusivos sobre creaciones literarias, artísticas o científicas y otros intereses generales o particulares, como puede ser el derecho de acceso a la cultura. La técnica vigente en el derecho comunitario europeo es la imposición de un elenco de límites al derecho de autor, con variedad de fundamentos y alcance, de los que se puede destacar el límite en favor de las personas con discapacidad visual u otras que dificulten el acceso a las obras impresas. En este artículo se estudia la implementación del referido límite en el derecho español.
\end{abstract}

Palabras clave: derecho de autor, límites, Tratado de Marrakech, discapacidad, personas con discapacidad visual, obras impresas

\begin{abstract}
The legal construction of copyright is based on the balance between the interests of the holders of exclusive rights on literary, artistic or scientific creations and other general or particular interests, such as the right of access to culture. The current technique in European community law is the imposition of a set of limits on copyright, with a variety of foundations and scope, of which the limit in favor of people with visual impairments or others that make access to printed works problematic. In this paper, the implementation of the aforementioned limit in Spanish law is studied.
\end{abstract}

Keywords: copyright, limitations, Marrakesh Treaty, disability, visually impaired, printed works 
31 ter de LA LEY DE PROPIEDAD INTEleCtual. 6.1. Elemento subjetivo: entidades autorizadas y beneficiarios. 6.2. Elemento objetivo: la obra accesible. 6.3. Usos autorizados. 6.4. Obligaciones de las entidades autorizadas. VII. ConCLUSIONES. VIII. BibLIOGRAFía.

\section{INTRODUCCIÓN: UN PUNTO DE PARTIDA EN EL RECONOCIMIENTO Y APOYO DE LA CREATIVIDAD SIN BARRERAS}

El objeto del presente artículo es un análisis crítico de la vigente regulación del límite al derecho de autor en favor de las personas con discapacidad visual u otras condiciones que dificulten el acceso a las obras impresas protegidas por la propiedad intelectual, en la legislación española, a partir de la transposición de la Directiva (UE) 2017/1564 que incorporó al derecho comunitario el nivel de protección contemplado en el Tratado de Marrakech para facilitar el Acceso a las Obras Publicadas para las personas ciegas, con discapacidad visual o con otras dificultades para acceder al texto impreso (TM).

A todos los efectos, se quiere, asimismo, poner de manifiesto que, a pesar de la importancia y alcance de la excepción a los derechos de propiedad intelectual aquí estudiada, se trata de una herramienta más en la agenda del fomento de la evolución del concepto de autonomía personal de las personas con discapacidad. No es un punto de llegada en la mejora de las condiciones de acceso a contenidos culturales y educativos por las personas con discapacidad visual, sino de una norma que debe ser interpretada en un marco general de fomento de medidas para el acceso universal a la cultura y el fomento de la creatividad.

\subsection{El acceso a contenidos culturales y formativos y el fomento de la creatividad}

La propuesta de estudio de un límite o excepción del derecho de autor en favor de las personas con discapacidad visual debe enmarcarse en una corriente más amplia de configuración de un derecho de acceso a la cultura y a la educación efectivo para las personas con discapacidad, por lo demás reconocido de una manera expresa en los artículos 24 y 30 de la Convención sobre los derechos de las personas con discapacidad, hecho en Nueva York el 13 de diciembre de 2006 (CDPD o Convención de Nueva York) ${ }^{1}$.

El acceso a la cultura y a la educación está en el sustrato de los límites y excepciones del derecho de autor ${ }^{2}$, debido a su condición de principal expediente técnico para alcanzar el equilibrio entre los diversos intereses en juego: autores, productores, editores, usuarios y sociedad en general.

Las facultades patrimoniales que integran la propiedad intelectual están sujetas a límites temporales y a una serie de excepciones al derecho exclusivo: cultura, aprendizaje, empleo, vida moderna y conexión humana permean la construcción de una categoría

1 Ratificado por España. Vid. BOE de 21 de abril de 2008.

2 Para un acercamiento a esta temática ANGUITA VILLANUEVA, L., «Derechos fundamentales y propiedad intelectual: el acceso a la cultura», en Propiedad Intelectual, Derechos Fundamentales y Propiedad Industrial (coord. César Iglesias Rebollo), Reus, Madrid, 2005, pp. 49-87 y SERRANO FERNÁNDEZ, M., «Acceso a la cultura y propiedad intelectual. El derecho de acceso a la cultura: su significado constitucional. La función social de la propiedad intelectual: la tutela del derecho de acceso a la cultura del art. 40 TRLPI», en Constitución y Propiedad Intelectual (coord. Luis Anguita Villanueva), Reus, Madrid, 2014, pp. 119-140. 
de derechos subjetivos sobre bienes inmateriales. Por ello, la relación entre educación, cultura y propiedad intelectual tiene una doble lectura, muy evidente en el contexto europeo. Por un lado, la propiedad intelectual genera cultura y favorece la transmisión del conocimiento y, por el otro, debe limitarse para no ser un freno al desarrollo de otros legítimos intereses.

En el caso que nos ocupa, limitar el derecho exclusivo de los autores y de titulares de otros derechos de propiedad intelectual tiene por objeto facilitar el acceso a obras impresas y, por ende, el acceso a la educación y a la cultura de las personas con discapacidad. Ello, además, incrementa el desarrollo de otros derechos fundamentales de las mismas, como el derecho a la no discriminación, el derecho a la información -pieza clave en la formación de una opinión pública fuerte-, el derecho al sufragio, entre otros.

Asimismo, no se puede dejar de tener en cuenta que ese límite también impulsa la creación literaria, artística o científica de las propias personas que se enfrentan a las barreras en el acceso a obras intelectuales, en cuanto el autor con discapacidad, en especial con imposibilidad o dificultad de lectura, se beneficia de un más elevado nivel de contenidos a su disposición.

El proceso creativo requiere y se fundamenta en el conocimiento de la tradición cultural y artística acumulada, de tal manera que un acceso más amplio a creaciones literarias, artísticas o científicas será fuente de mayor creatividad en las personas con capacidades diversas, a fin de hacer efectivo el ejercicio del derecho fundamental a la producción y creación literaria, artística, científica y técnica, reconocido expresamente en el artículo 20.1.b) de la Constitución española (CE).

Estamos potenciando el número de eventuales autores. La persona creadora con discapacidad adquiere un nuevo protagonismo, pues se tiene en cuenta, además de su faceta de consumidor de materiales protegidos, su potencial creador de contenidos originales.

\subsection{La accesibilidad universal como objetivo}

De acuerdo con los artículos 3(f) y 9 CDPD, los Estados deben tomar una serie de medidas para asegurar que las personas con discapacidad puedan acceder, entre otras cosas, a la información y a las comunicaciones, como una condición previa para la vida independiente y para la participación plena en todos los aspectos de la vida.

En particular, la necesidad de desarrollar estrategias inclusivas tiene como uno de los tópicos más inmediato la eliminación de brechas tecnológicas, con el fin de crear entornos físicos e intelectuales accesibles para las personas con diversidades funcionales.

Las excepciones y limitaciones al derecho de autor previstas por el Tratado de Marrakech, pese a su importancia, no garantizan que obras nuevas se publiquen en formatos digitales accesibles desde el principio, y que estén inmediatamente disponibles para las personas con discapacidad sin necesidad de adaptaciones posteriores. De ahí que sea solo un punto de partida hacia la accesibilidad universal.

De lo que se trata es de combinar distintos enfoques, a la hora de alcanzar el objetivo final de igualdad de acceso. En ese sentido, tan importante como adaptar los formatos originales de las obras para que personas con diversidad funcional tengan acceso a las mismas es diseñar nuevas tecnologías pensando en un acceso universal desde el princi- 
pio, sin necesidad de adaptaciones por intermediarios, disminuyendo razonablemente la excepcionalidad del acceso.

En el ámbito de la discapacidad visual, el desarrollo de las diferentes tecnologías tiflotécnicas ${ }^{3}$ estuvieron inicialmente basadas en el primer enfoque, es decir, proporcionar dispositivos que faciliten el acceso adaptado a las obras. El diseño del límite al derecho de autor en favor de las personas con discapacidad visual se ha gestado en ese entorno.

Ahora bien, se deja una invitación a explorar las potencialidades de las nuevas tecnologías de acceso y, consecuentemente, de estímulo creador de en la industria 4.0, en particular, la inteligencia artificial, ahora bajo la perspectiva del diseño de la accesibilidad desde el inicio ${ }^{4}$. Es un paso más en el camino de la inclusión de las personas con diversidad funcional a través de una perspectiva activa, menos asistencialista, con el ser humano en el centro de la atención de los problemas jurídicos. Se trata de que ahora «las tecnologías desde el mismo momento de su concepción, diseño y producción incorporen las máximas de «Diseño para Todos» de manera que, teniendo en cuenta las necesidades del conjunto de sus usuarios, se favorecerá su acceso en igualdad de condiciones con independencia de su condición cultural, social, de salud o discapacidad $»^{5}$.

En ese sentido, la persona con discapacidad visual se transforma en un consumidor de contenidos digitales protegidos por el derecho de autor en la misma posición que cualquier otro consumidor de bienes y servicios.

\section{LÍMITES DEL DERECHO DE AUTOR. LA REGLA DE LOS TRES PASOS}

En sus orígenes, el derecho de autor se ha concebido como un derecho subjetivo limitado, de tal forma que, adicionalmente a las limitaciones generales de plazo, se fueron diseñando unas cuantas excepciones específicas para romper o suavizar el régimen de exclusividad otorgada a los titulares de derechos, en aras de un mayor equilibrio entre el derecho de los autores y otros intereses jurídicos legítimos ${ }^{6}$.

3 La tiflotecnología (del griego «tiflos», ciego) es el conjunto de técnicas, conocimientos y recursos para procurar a las personas con discapacidad visual los medios oportunos para la correcta utilización de la tecnología. Proporciona los instrumentos auxiliares, ayudas o adaptaciones tecnológicas, creadas o adaptadas específicamente para posibilitar a las personas con ceguera, discapacidad visual o sordoceguera la correcta utilización de la tecnología, contribuyendo a su autonomía personal y plena integración social, laboral y educativa.

4 Son varios los trabajos e iniciativas que ponen de manifiesto que las personas con discapacidad son un grupo vulnerable, especialmente expuesto al riesgo de vulneración de sus derechos y libertades fundamentales, que deben ser tenidos en cuenta para un anhelado diseño para todas las personas y accesibilidad universal. Vid., con carácter general, VIVAS TESÓN, I., «El ejercicio de los derechos de la personalidad de la persona con discapacidad», en Claves para la adaptación del Ordenamiento jurídico privado a la Convención de Naciones Unidas en materia de discapacidad, (dirs. De Salas y Mayor del Hoyo), Tirant lo Blanch, Valencia, 2019, pp. 409-443.

5 Entrada «Trifotecnología» en la web de la ONCE. Disponible en https://www.once.es/servicios-sociales/ tecnologiayrecursosadaptados/tiflotecnologia

6 En este trabajo, se utilizan los términos límites, limitaciones o excepciones como sinónimas, sin desconocer las discusiones doctrinales que colocan la idea de límite como más acertada, pues entienden que la regla general es la libertad, frente a aquellos que, por el contrario, consideran el derecho de autor es absoluto y eventualmente puede soportar algunas limitaciones o excepciones, expresiones que bajo ese punto de vista serían más apropiadas. Vid. GEIGER, C., Droit d'auteur et droit du public à l'information: approche de droit comparé, Litec, París, 2004, pp. 194-195. 
Ello permite afirmar que el derecho de autor es un derecho subjetivo de equilibrio ${ }^{7}$, que se define por la convivencia entre exclusividad y flexibilidad en su estructura normativa.

Ahora bien, siempre que una norma trata de limitar cualquier derecho subjetivo es preciso encontrar argumentos de peso y perfilar mecanismos que no vacíen de contenido el derecho limitado, a la vez que atiendan a los fines propuestos por el legislador.

Son varios los límites del derecho de autor que están relacionados de una manera más o menos directa con la actividad didáctica de enseñanza y con la investigación, respondiendo a las exigencias de garantía de los derechos contenidos en los artículos $27 \mathrm{CE}$ (derecho fundamental a la educación) y $40 \mathrm{CE}$ (principios rectores de acceso a la cultura y de promoción de la ciencia y la investigación científica y técnica).

Aparte de la que específicamente se refiere a la ilustración de la enseñanza, no cabe la menor duda de que otras excepciones facilitan el acceso legal y libre a contenidos didácticos, en algunos de los supuestos con licencias remuneradas y en otros no. Es el caso del denominado derecho de cita (de los que muchos entienden que la ilustración para la enseñanza es una especie), la copia privada, limitaciones y excepciones en favor de las bibliotecas y archivos, más recientemente las obras huérfanas, etc.

Ese entramado de posibilidades de utilización de las obras favorece la ductilidad del derecho de autor, y funciona como garantía de acceso legal a la cultura y al conocimiento a través de contenidos protegidos por la propiedad intelectual ${ }^{8}$, sin necesidad de la autorización de sus titulares.

Es aquí, en este punto, en el que se puede ubicar la configuración de un límite que favorezca que personas con una discapacidad visual $u$ otras dificultades para la lectura puedan acceder a la obra protegida en un formato accesible.

Ahora bien, la configuración normativa de cualquier límite a los derechos de autor y conexos, así como su aplicación, deben obedecer unos parámetros que no hagan que la limitación sea insoportable para los intereses de los titulares de derechos, pues caso contrario, representarían un desincentivo a la creación y a la producción de contenidos.

Entra en escena la conocida regla de los tres pasos, introducida en el Convenio de Berna en su reforma de 1967, en relación con el derecho de reproducción. Posteriormente, la Organización Mundial del Comercio adoptó una norma similar en su Acuerdo sobre los ADPIC de 1995, extendiéndola a cualquier límite o excepción. Por ejemplo, en su introducción en el derecho español, por medio de la transposición de la Directiva 96/9/ CE, de 11 de marzo de 1996, sobre la protección jurídica de las bases de datos, el vigente artículo 40 bis LPI determina que los artículos del Capítulo dedicado a los límites del derecho de autor «no podrán interpretarse de manera tal que permitan su aplicación de forma que causen un perjuicio injustificado a los intereses legítimos del autor o que vayan en detrimento de la explotación normal de las obras a que se refieran».

7 CARON, C., «Les exceptions au regard du fondement du droit d'auteur en droit français», Les exceptions au Droit D'Auteur. État des lieux et perspectives dans l'Union européenne (dirs. André Lucas, Pierre Sirinelli, Alexandra Bensamoun), Dalloz, París, 2012, p. 21.

8 Cuando la DDASI, en su Considerando 14, indica como objetivo «fomentar el aprendizaje y la cultura mediante la protección de las obras y prestaciones, permitiendo al mismo tiempo excepciones o limitaciones en interés general para fines educativos y docentes», a continuación presenta una serie de límites y excepciones que proporcionan un espacio para el uso libre de los derechos de autor. Excepciones como la cita, la parodia, la ilustración, etc. Todas ellas permiten la circulación del conocimiento y el refuerzo del contenido de las enseñanzas. 
Por lo tanto, la construcción convencional de la referida regla está hecha sobre la base de que:

1. esté previsto en casos especiales la limitación o excepción,

2. que no afecte a la explotación normal del derecho de que se trate, y

3. que no cause un perjuicio injustificado a los intereses del titular.

Asimismo, las etapas así acordadas alcanzan tanto la fase de creación normativa como el momento de la aplicación del límite creado, de tal manera que la finalidad de esa regla es, por un lado, no imponer una limitación excesiva y no justificada a los derechos exclusivos de propiedad intelectual y, por otra parte, evitar distorsiones en el mercado. Se configura como un «límite de límites», ya que permite rechazar acciones amparadas en la legalidad, pero que sobrepasan la función, el espíritu, previsto por el legislador para justificar la excepción?.

En el período de la elaboración legislativa es un freno para los Estados a la hora de imponer limitaciones a la exclusividad derivada del reconocimiento de derechos de propiedad intelectual. En la fase de aplicación de la norma, está concebida como regla de interpretación, como es el caso del citado artículo 40 bis LPI dirigido a la interpretación de los límites recogidos por la ley

Pues bien, como se verá a continuación, la negociación de un Tratado internacional para la protección de las personas con discapacidad visual tuvo presente en todo momento esa necesidad de equilibrio entre, por una parte, la necesaria protección del derecho a la cultura y a la educación, sin discriminación, de las personas con discapacidad y, por otra, la preocupación por una limitación excesiva de los legítimos intereses de los creadores y de otros agentes económicos implicados en la propiedad intelectual.

\section{EL TRATADO DE MARRAKECH. SOBRE LA NECESIDAD DE INTRODUCCIÓN DEL LÍMITE}

No se puede entender el éxito de las negociaciones del TM sin tener presente la aprobación en el año 2006 de la Convención de Nueva York.

La CDPD está anclada sobre la base de la promoción de la autonomía de la persona con discapacidad, situándola en el mismo plan de igualdad que las demás personas. Se aleja del modelo médico y asistencialista, camino de una representación de la discapacidad que permita la normalización de las diferencias. Por lo tanto, la existencia de barreras en el acceso a los materiales impresos para mejorar el nivel formativo y para acceder a la cultura es contraria a la CDPD.

Esa concepción de la discapacidad basada en los derechos humanos hace hincapié en las barreras, no en las diferencias entre los sujetos ${ }^{10}$. A modo de ejemplo, se puede

9 Como explica MARTÍN SALAMANCA, S., «Derecho de autor», en Derecho de la propiedad intelectual: derecho de autor y propiedad industrial (dir. Miguel Ruiz Muñoz), Tirant lo Blanch, Valencia, 2017, pp. 100 y 101.

10 Señala VIVAS TESÓN que la CDPD ha conllevado un cambio paradigmático de actitud y enfoque respecto de la discapacidad a nivel mundial. Se mira la discapacidad con otros ojos, en clave de derechos humanos. La Convención advierte a España y a los restantes Estados así como a las Organizaciones supranacionales (como 
citar como ensayo de adaptación normativa la definición de discapacidad contenida en artículo 4 del Real Decreto Legislativo 1/2013: «Son personas con discapacidad aquellas que presentan deficiencias físicas, mentales, intelectuales o sensoriales, previsiblemente permanentes que, al interactuar con diferentes barreras, pueden impedir su participación plena y efectiva en la sociedad, en igualdad de condiciones con los demás».

En ese contexto, uno de sus propósitos básicos para la consecución de la igualdad pretendida por la CDPD es la accesibilidad del entorno físico, social, económico y cultu$\mathrm{ral}^{11}$, condición para la plena participación en sociedad y el disfrute de derechos ${ }^{12}$.

Por ello, en el año 2006, la Organización Mundial de la Propiedad Intelectual (OMPI) realizó un estudio que analizaba la situación de las excepciones en favor de personas con discapacidad e indicó que únicamente 60 países tenían algún tipo de regulación sobre la materia. Se suele indicar que es la primera vez que por iniciativa de la OMPI se promueve un Tratado centrado en los intereses de usuarios de derechos de autor y conexos.

Con ese punto de partida, organizaciones como la Unión Mundial de personas ciegas (UMC) tomaron la iniciativa de un Tratado internacional que facilitase la producción e intercambio transfronterizo de obras protegidas por el derecho de autor en formatos accesibles a las personas ciegas, con discapacidad visual o cualquier otra condición que dificulte el acceso a obras impresas.

La discapacidad visual es una realidad con la que se enfrenta una parte significativa de la población mundial. De acuerdo con las estimaciones de la OMS, en el año 2010, 285 millones de personas del mundo entero sufrían discapacidad visual y 39 millones de ellas eran ciegas ${ }^{13}$. En el caso de Europa, con ocasión de la implementación del TM, se manejaba la cifra de 30 millones de personas con discapacidad visual.

Con el protagonismo de la UMC, activa impulsora del TM, las negociaciones arrancaron con la constatación de que sólo un 7\% de las publicaciones se ponen a disposición global en formatos accesibles, y en el mundo en vías de desarrollo, donde vive el $90 \%$ de las personas ciegas o deficientes visuales, la cifra es menor del $1 \%{ }^{14}$. Con más del $90 \%$ de los materiales que se publican inaccesibles para las personas ciegas o con gran dificultad de lectura de la letra impresa, la UMC reivindicaba poder reproducirlos en formatos accesibles, tales como braille, macrotipo y audio, con el fin de que los estu-

la Unión Europea) firmantes que el único abordaje que puede hacerse de la discapacidad es desde los derechos humanos y libertades fundamentales de la persona. VIVAS TESÓN, I., «El ejercicio de los derechos de la personalidad», cit., p. 411.

11 VIVAS TESÓN, I., «El ejercicio de los derechos de la personalidad», cit., pp. 413-414, sostiene que la CDPD reconoce un nuevo derecho, el derecho a la accesibilidad universal (no sólo arquitectónica), entendiendo por tal el ejercicio accesible y efectivo de los todos los derechos para tener una vida plena e independiente. Sólo así se da cumplimiento a los arts. 12 y 19 de la Convención. Por ello, considera que la accesibilidad se erige como un nuevo derecho de la personalidad: «la no accesibilidad a los derechos es una flagrante violación de la dignidad humana, puesto que si los derechos reconocidos a todas las personas sin excepción no pueden disfrutarse plena y efectivamente no puede vivirse una vida digna».

12 HELFER, L.R., Guía del Tratado de Marrakech de la Unión Mundial de Ciegos, 2016. Disponible en http:// www.worldblindunion.org/Spanish/Our-work/our-priorities/Pages/La-Guía-de-la-Unión-Mundial-de-Ciegos-alTratado-de-Marrakech.aspx, p.30.

13 También señalaba que el $82 \%$ de las personas ciegas y el $65 \%$ de las personas con ceguera moderada o grave eran mayores de 50 años. Las poblaciones pobres se ven más afectadas por las discapacidades visuales como la ceguera. Cfr. el Informe de Secretaría de la OMS « Proyecto de plan de acción para la prevención de la ceguera y la discapacidad visual evitables 2014-2019», núm. A 66/11, de 28 de marzo de 2013.

14 OMPI, El Tratado de Marrakech - Hacia la erradicación del hambre mundial de libros, Ginebra, 2016. 
diantes ciegos pudiesen incrementar su preparación y su educación formal. Y, de hecho, el Preámbulo del TM destaca que

«Reconociendo que muchos Estados miembros han establecido excepciones y limitaciones en su legislación nacional de derecho de autor destinadas a las personas con discapacidad visual o con otras dificultades para acceder al texto impreso, pero que sigue siendo insuficiente el número de ejemplares disponibles en formatos accesibles para dichas personas; que son necesarios recursos considerables en sus esfuerzos por hacer que las obras sean accesibles a esas personas; y que la falta de posibilidades de intercambio transfronterizo de ejemplares en formato accesible hace necesaria una duplicación de esos esfuerzos».

Con estos mimbres, el TM - adoptado el 27 de junio de $2013^{15}$ - forma parte del cuerpo de tratados internacionales sobre derecho de autor administrados por la OMPI. El foco se puso en el derecho de acceso a la cultura y a la educación como derechos humanos y se acuñó la expresión «hambre mundial de libros» ${ }^{16}$.

El TM crea un marco legal internacional que permite producir y distribuir ejemplares en formatos accesibles para personas con dificultades para acceder al texto impreso, así como compartirlos de forma transfronteriza En el Preámbulo del TM se proclaman los principios de no discriminación, igualdad de oportunidades y plena y efectiva participación e inclusión en la sociedad, presente es la CDPD y en la Declaración Universal de los Derechos Humanos.

Desde un punto de vista más técnico, se diseña un límite exclusivamente para las personas con discapacidad. Es decir, no se recurre a otros límites ya existentes y consolidados, como el caso de la copia privada, sino que se crea una fórmula adaptada a los objetivos propuestos. En realidad, la excepción de la copia privada no es idónea para cubrir las necesidades del colectivo de personas con discapacidades visuales ${ }^{17}$, pues precisamente su problema es la dificultad o imposibilidad de acceso legítimo a la obra protegida en el formato (analógico o digital) que no cumple con los estándares técnicos de accesibilidad ${ }^{18}$.

La clave se encuentra en un formato accesible y en la asistencia de un tercero para obtener la copia accesible ${ }^{19}$. En efecto, el TM define «ejemplar en formato accesible» como la reproducción de una obra de forma alternativa y accesible a las necesidades de los beneficiarios. Por ese motivo, el límite no alcanza aquellas obras que han sido creadas y comercializadas para un público de personas con discapacidad visual, sino que está referido a obras que precisan ser adaptadas para su acceso por personas con discapacidad.

15 El TM entró en vigor el 30 septiembre 2016, tras alcanzar la ratificación mínima de 20 Estados.

16 OMPI, El Tratado de Marrakech, cit., y HELFER L.R. et al, Guía, cit. 2016, p.8.

17 Aunque algunos autores buscaron la conexión: MARTÍN SALAMANCA, S., «Artículo 31 bis», en Comentarios a la Ley de Propiedad Intelectual (dir. José Miguel Rodríguez Tapia), Thomson Reuters-Civitas, Cizur Menor (Navarra), 2007, p. 250 y LÓPEZ SÁNCHEZ, C., «La utilización de una obra intelectual a favor de personas con discapacidad», en Límites a la propiedad intelectual y nuevas tecnologías (coord. Juan Antonio Moreno Martínez), Dykinson, Madrid, 2008, p. 611

18 Téngase en cuenta que el artículo 31.2 LPI indica que deben concurrir simultáneamente las siguientes circunstancias para configurar el límite legal de copia privada: a) que se lleve a cabo por una persona física exclusivamente para su uso privado, no profesional ni empresarial, y sin fines directa ni indirectamente comerciales; b) que la reproducción se realice a partir de una fuente lícita y que no se vulneren las condiciones de acceso a la obra o prestación; y c) que la copia obtenida no sea objeto de una utilización colectiva ni lucrativa, ni de distribución mediante precio.

19 LÓPEZ MAZA destaca la asistencia de terceros como uno de los elementos diferenciadores del límite sobre copia privada [LÓPEZ MAZA, S., «Comentario al artículo 31 bis», en Comentarios a la Ley de Propiedad Intelectual (dir. Rodrigo Bercovitz), Tecnos, Madrid, 2017, p. 611]. 
Las Partes Contratantes del Tratado asumen el compromiso de introducir en sus ordenamientos límites a los derechos de reproducción, distribución y comunicación pública -incluido en este concepto la puesta a disposición en línea-de obras publicadas en formatos accesibles para las personas ciegas, con discapacidad visual u otras dificultades para acceder al texto impreso, y permitir el intercambio transfronterizo de esas obras por las organizaciones que están al servicio de los beneficiarios.

En todo caso, el TM no impone la obligación de proporcionar ejemplares en formatos accesibles, sino que simplemente otorga el derecho de producirlos, suministrarlos, importarlos y exportarlos ${ }^{20}$

Los beneficiarios, en los términos del artículo 3 TM son las personas ciegas, las que padezcan una discapacidad visual o quien por una discapacidad física no pueda sostener ni manipular un libro, centrar la vista o mover los ojos. Es el estándar mínimo que deben proteger los Estados que ratifican el TM y alcanza cualquier tipo de discapacidad, no exclusivamente la visual, que impida o dificulte de una forma severa la lectura. En ese sentido, se incluye tanto la discapacidad visual (ceguera o baja visión) como una discapacidad evolutiva o de aprendizaje, como la dislexia y el autismo, o una discapacidad física, por ejemplo, la enfermedad de Parkinson y cualquier tipo de parálisis que origine dificultades de lectura. Asimismo, no es necesario que la discapacidad sea permanente ${ }^{21}$.

Pero para realizar las tareas de adaptación del formato, es insoslayable la intervención de terceros -asociaciones, bibliotecas, etc.- que son denominadas por el TM «entidad autorizada». En los términos del artículo 2(c) TM, por «entidad autorizada» se entenderá toda entidad autorizada o reconocida por el gobierno para proporcionar a los beneficiarios, sin ánimo de lucro, educación, formación pedagógica, lectura adaptada o acceso a la información ${ }^{22}$. Se entenderá también toda institución gubernamental u organización sin ánimo de lucro que proporcione los mismos servicios a los beneficiarios, como una de sus actividades principales $\mathrm{u}$ obligaciones institucionales.

Las entidades autorizadas juegan un papel decisivo en el control del ámbito de la utilización de las obras. De hecho, esta limitación o excepción en particular exige la utilización exclusiva de las obras por los beneficiarios; y el TM indica la obligación de que las entidades autorizadas, antes de esa distribución o puesta a disposición, utilicen una diligencia razonable para determinar que la persona que accede cumple los requisitos de beneficiaria, asimismo, deben desalentar la reproducción, distribución y puesta a disposición de ejemplares no autorizados y ejercer la diligencia debida en el uso de los ejemplares de las obras, y mantener registros de dicho uso, respetando la intimidad de los beneficiarios.

La preocupación por la racionalización de la producción y acceso a esos materiales se manifiesta en la exigencia de que las Partes Contratantes permitan la importación y exportación de ejemplares en formato accesible, en determinadas condiciones. En lo que atañe a la importación, cuando la legislación nacional permita realizar un ejemplar

20 IFLA, Implementar el Tratado de Marrakech para personas con dificultades para acceder al texto impreso de acuerdo con la legislación española, Guía para bibliotecarios, IFLA/ONCE, p. 14. Disponible en https://www.ifla.org/files/assets/hq/topics/exceptions-limitations/ponerse_en_marcha_ley_espanola.pdf 21 HELFER L.R. et al, Guía, cit., p. 47.

22 Un actor protagonista de la implementación de este Tratado son las bibliotecas, como se puede comprobar en IFLA, Implementar, cit., p. 12, y EIFL, Guía EIFL (Electronic Information for Libraries) para bibliotecas. El Tratado de Marrakech para facilitar el acceso a las obras publicadas para las personas ciegas, con discapacidad visual, o con otras dificultades para acceder al texto impreso, 2015. 
en formato accesible, también se podrá importar un ejemplar en formato accesible sin la autorización del titular de los derechos. Respecto de la exportación, una entidad autorizada podrá distribuir o poner a disposición de un beneficiario o una entidad autorizada de otra Parte Contratante los ejemplares en formato accesible realizados en el marco de una limitación o excepción u otra norma.

Precisamente esa posibilidad de que las obras en formato accesible puedan enviarse a otros países para su utilización en bibliotecas o asociaciones abiertas a las personas con discapacidad visual es uno de los mayores logros del Tratado. Con ello, se permite que instituciones con importantes colecciones de libros accesibles puedan compartirlas con países de menos recursos ${ }^{23}$.

Con el tiempo, se pretende reunir en una única base de datos mundial las referencias al material disponible en formato accesible. Para facilitar el conocimiento del acervo accesible ya existente, el TM exige que la OMPI establezca un «punto de acceso a la información» que permita el intercambio voluntario de información que facilite la identificación de las entidades autorizadas.

Resumiendo, para que entre en juego la excepción es preciso que:

a. Sean obras publicadas;

b. Se materialice a través de ejemplares obtenidos lícitamente;

c. La reproducción se realice por medio de las entidades autorizadas al efecto;

d. Tenga lugar en un sistema que permita el acceso a los beneficiarios;

e. Sea para el uso exclusivo de los beneficiarios;

f. Todo se desarrolle sin ánimo de lucro

Ahora bien, como cualquier otra excepción al derecho exclusivo es menester que no provoque un perjuicio injustificado a los intereses legítimos de los autores. De ahí que el TM formule la excepción según los parámetros interpretativos de las tres etapas.

En todo caso, se trata de garantizar que la merma del derecho de la integridad sea razonable, limitada al uso restringido a los parámetros establecidos por la norma. En esa línea, el artículo 2 (B) del Tratado de Marrakech define «ejemplar en formato accesible» como «la reproducción de una obra, de una manera o forma alternativa que dé a los beneficiarios acceso a ella, siendo dicho acceso tan viable y cómodo como el de las personas sin discapacidad visual o sin otras dificultades para acceder al texto impreso. El ejemplar en formato accesible será utilizado exclusivamente por los beneficiarios y debe respetar la integridad de la obra original, tomando en debida consideración los cambios necesarios para hacer que la obra sea accesible en el formato alternativo y las necesidades de accesibilidad de los beneficiarios. ${ }^{24}$

23 EIFL, Guía, cit., p.6.

24 Téngase en cuenta el artículo 6 bis del Convenio de Berna que define el derecho de integridad como la posibilidad de «oponerse a cualquier deformación, mutilación u otra modificación de la misma o a cualquier atentado a la misma que cause perjuicio a su honor o a su reputación». En el artículo 14. 4 LPI corresponde al autor el derecho moral inalienable e irrenunciable a «exigir el respeto a la integridad de la obra e impedir cualquier deformación, modificación, alteración o atentado contra ella que suponga perjuicio a sus legítimos intereses o menoscabo a su reputación.» 
El anhelo de alcanzar un sistema que aúne la seguridad jurídica del elenco de limitaciones y excepciones al derecho de propiedad intelectual, y una mayor flexibilidad en su configuración y aplicación, tiene su campo de pruebas en la interpretación que se haga de la denominada regla de las tres etapas o de los tres pasos.

En el caso concreto del límite a los derechos de explotación a favor de las personas con discapacidad, este reto se alcanza con una correcta configuración del concepto de formato accesible y de sujetos beneficiarios. Se puede hablar de un límite relacionado con la función social de la propiedad intelectual ${ }^{25}$, y como se ha puesto de manifiesto, del primero Tratado de derecho de autor con un fundamento esencialmente humanitario ${ }^{26}$.

Por último, no se puede cerrar un análisis del TM, sin recordar que su artículo 8, bajo el epígrafe de respeto a la intimidad, establece que en la puesta en práctica de las limitaciones y excepciones contempladas en el presente Tratado, las Partes Contratantes harán lo posible por proteger la intimidad de los beneficiarios en igualdad de condiciones con las demás personas.

\section{EL ÁMBITO COMUNITARIOLAS DIRECTIVAS 96/9/CE (3), 2001/29/CE(4),2006/115/CE(5)Y2009/24/CE(6)DELPARLAMENTO EUROPEO Y DEL CONSEJO ARMONIZAN LOS DERECHOS DE LOS TITULARES EN EL ÁMBITO DE LOS DERECHOS DE AUTOR Y LOS DERECHOS AFINES. ESTAS DIRECTIVAS, JUNTO CON LA DIRECTIVA 2012/28/UE: LA DIRECTIVA (UE) 2017/1564}

En virtud de la Carta de Derechos Fundamentales de la Unión Europea, artículos 21 y 26, está prohibida toda forma de discriminación, también por motivos de discapacidad, y la Unión reconoce y respeta el derecho de las personas con discapacidad a beneficiarse de medidas que garanticen su autonomía, su integración social y profesional y su participación en la vida de la comunidad.

La Directiva 2001/29/CE (DDASI) es uno de los instrumentos más destacados del derecho comunitario regulador de la propiedad intelectual, en cuanto configura los aspectos básicos de los derechos explotación de la obra, así como de sus límites o excepciones ${ }^{27}$. En ella, se puede encontrar una preocupación con el tema del acceso a las

25 MARTÍN SALAMANCA, S., «Artículo 31 bis», cit., p. 251 y CASTELLÓ PASTOR, J.J., «Comentario al artículo 31 bis», en Comentarios a la Ley de Propiedad Intelectual (dirs. Felipe Palau Ramírez y Guillermo Palao Moreno), Tirant lo Blanch, Valencia, 2017, p. 516.

26 IFLA, Guía, cit., p. 12 y XALABARDER, R., «Implementación del Tratado de Marrakech para facilitar el acceso a obras protegidas por personas con discapacidad visual. Crónica de legislación, en Ars Iuris Salmanticensis, vol. 6, junio 2018, p. 255.

27 Completan la regulación de los límites en la UE las Directivas 96/9/CE, 2006/115/CE, 2009/24/CE, 2012/28/UE y más recientemente 2019/790/UE.Las Directivas 96/9/CE (3), 2001/29/CE (4), 2006/115/CE (5) y 2009/24/CE (6) del Parlamento Europeo y del Consejo armonizan los derechos de los titulares en el ámbito de los derechos de autor y los derechos afines. Estas Directivas, junto con la Directiva 2012/28/UE Las Directivas 96/9/CE (3), 2001/29/CE (4), 2006/115/CE (5) y 2009/24/CE (6) del Parlamento Europeo y del Consejo armonizan los derechos de los titulares en el ámbito de los derechos de autor y los derechos afines. Estas Directivas, junto con la Directiva 2012/28/UE Las Directivas 96/9/CE (3), 2001/29/CE (4), 2006/115/CE (5) y 2009/24/CE (6) del Parlamento Europeo y del Consejo armonizan los derechos de los titulares en el ámbito de los derechos de autor y los derechos 
creaciones por las personas con discapacidad reflejada en el artículo 5.3. b) que recoge la posibilidad (no la obligación) de que los Estados miembros «puedan establecer excepciones o limitaciones a los derechos de reproducción y comunicación o puesta a disposición al público cuando el uso se realice en beneficio de personas con minusvalías, guarde una relación directa con la minusvalía y no tenga un carácter comercial, en la medida en que lo exija la minusvalía considerada».

Ese fue un importante avance, si tenemos en cuenta que el contexto europeo anterior a la entrada en vigor de la DDASI era poco favorable a una excepción a favor de las personas con discapacidad, pues - con la salvedad de Finlandia, Noruega, Suecia, Portugal y España- prevalecía la protección de los derechos de propiedad intelectual ${ }^{28}$ sobre otros intereses sociales.

Como consecuencia de la necesaria transposición de la DDASI, varios Estados miembros introdujeron (o adaptaron un límite ya reconocido) en sus legislaciones una excepción a los derechos de reproducción y comunicación o puesta a disposición al público cuando el uso se realizase en beneficio de personas con discapacidad, pero al tratarse de un límite facultativo, el resultado fue, al igual que lo ocurrido con otros límites, una escasa armonización debido a la disparidad de criterios normativos en la adaptación realizada por los diferentes países de la Unión.b) cuando el uso se realice en beneficio de personas con minusvalías, guarde una relación directa con la minusvalía y no tenga un carácter comercial, en la medida en que lo exija la minusvalía considerada; b) cuando el uso se realice en beneficio de personas con minusvalías, guarde una relación directa con la minusvalía y no tenga un carácter comercial, en la medida en que lo exija la minusvalía considerada;

El escenario cambia cuando el 30 de abril de 2014 se firmó, en nombre de la UE, el $\mathrm{TM}^{29}$. La implementación del Tratado se plasma en la Directiva (UE) $2017 / 1564^{30}$, cuyo objeto, descrito en su Considerando 7, es mejorar la disponibilidad de libros, incluidos los libros electrónicos, diarios, periódicos, revistas y otros tipos de textos escritos, notaciones, incluidas partituras ${ }^{31}$, y otros materiales impresos, también en formato audio, tanto digital como analógico, en línea o no, en formatos que permitan a esas personas acceder a esas obras y otras prestaciones en una medida sustancialmente equivalente a la de las personas sin dichas discapacidades o dificultades.

Para ello, se establece una excepción, ahora imperativa, que limita los derechos de reproducción, distribución y comunicación pública que, en todo caso, deben aplicarse en el marco del ámbito armonizado por la Directiva 2001/29/CE ${ }^{32}$. De ese modo, todos los

afines. Estas Directivas, junto con la Directiva 2012/28/UE Las Directivas 96/9/CE (3), 2001/29/CE (4), 2006/115/ CE (5) y 2009/24/CE (6) del Parlamento Europeo y del Consejo armonizan los derechos de los titulares en el ámbito de los derechos de autor y los derechos afines. Estas Directivas, junto con la Directiva 2012/28/UE

28 De esta manera lo describe LÓPEZ SANCHEZ, C., «La utilización de una obra intelectual», cit., p.245.

29 Decisión 2014/221/UE del Consejo, de 14 de abril de 2014, relativa a la firma, en nombre de la Unión Europea, del Tratado de Marrakech para facilitar el acceso a las obras publicadas a las personas ciegas, con discapacidad visual o con otras dificultades para acceder al texto impreso (DOUE de 17 de abril de 2014).

30 DOUE de 20 de septiembre de 2017.

31 La musicografía Braille es un sistema de notación musical desarrollado por Louis Braille de forma conjunta al sistema de lectura para el texto.

32 Así lo explicita el Dictamen del Tribunal de Justicia de la Unión Europea de 14 de febrero de 2017, 3/15, ECLI:EU:C:2017:114, apartado 112. 
Estados miembros están obligados a introducir el límite en sus legislaciones, ya no es una opción no hacerlo, como ocurría con la DDASI.

Dicha excepción imperativa debe limitar el derecho de reproducción, con el fin de permitir que se puedan tomar todas las medidas necesarias para modificar, convertir o adaptar cualquier obra u otra prestación de modo que se produzca un ejemplar en formato accesible que permita a los beneficiarios acceder a esa obra o prestación. Ello incluye la facilitación de los medios necesarios para consultar la información de un ejemplar en un formato accesible; $y$, asimismo, también abarca los cambios que puedan requerirse en los casos en que el formato de una obra u otra prestación ya sea accesible para algunos beneficiarios, pero no lo sea para otros, debido a las distintas discapacidades o dificultades, o el distinto grado de dichas discapacidades o dificultades ${ }^{33}$.

De obligada aplicación, el único margen para la transposición de la Directiva (UE) 2017/1564 es la libertad para la imposición de una remuneración compensatoria por el límite. Para aquellos Estados que opten por exigir una remuneración, se establece que a la hora de determinar el nivel de compensación, deba tenerse debidamente en cuenta la naturaleza no lucrativa de las actividades de las entidades autorizadas, los objetivos de interés público perseguidos por la Directiva, los intereses de los beneficiarios de la excepción, el posible perjuicio para los titulares de los derechos y la necesidad de garantizar la difusión transfronteriza de ejemplares en formatos accesibles. También deben considerarse las circunstancias que se deriven en cada caso de la producción de un ejemplar concreto en formato accesible. Asimismo, en aplicación de la regla de minimis non curat lex, en aquellos supuestos en que el perjuicio causado al titular del derecho sea mínimo, no debe generarse obligación alguna de compensación.

El contenido básico de la Directiva recoge en esencia el $\mathrm{TM}^{34}$, adaptando algunos aspectos para hacerlos compatibles con el derecho comunitario. Como resume XALABARDER, el límite alcanza tanto a los derechos de autor como a los conexos, afecta también al derecho de disposición al público, se refiere tanto a las obras como a otras prestaciones protegidas, y de igual modo al derecho sui generis del fabricante de bases de datos ${ }^{35}$.

En suma, el fundamento del límite se encuentra descrito en el Considerando 3 de la Directiva:

«Las personas ciegas, con discapacidad visual o con otras dificultades para acceder a textos impresos siguen enfrentándose a numerosas barreras para poder acceder a libros y otros materiales impresos protegidos por derechos de autor y derechos afines. Tomando en consideración los derechos de las personas ciegas, con discapacidad visual o con otras dificultades para acceder a textos impresos, tal y como se encuentran reconocidos en la Carta de los Derechos Fundamentales de la Unión Europea (en lo sucesivo, «Carta») y en la Convención de las Naciones Unidas sobre los Derechos de las Personas con Discapacidad (en lo sucesivo, «Convención»), deben tomarse medidas para aumentar la disponibilidad de libros y otros materiales impresos en formatos accesibles, así como para mejorar su circulación en el mercado interior».

33 Considerando 8 de la Directiva (UE) 2017/1564.

34 En particular, hace efectiva la norma contenida en el artículo del artículo 7 TM que prohíbe la restricción al acceso a las obras por medio de medidas tecnológicas.

35 XALABARDER, R., «Implementación del Tratado», cit., p. 256. 
Por último, por lo que a producción normativa se refiere, en el ámbito comunitario, es necesario tener en cuenta, también, el Reglamento (UE) 2017/1563 del Parlamento Europeo y del Consejo, de 13 de septiembre de $2017^{36}$, sobre el intercambio transfronterizo entre la Unión y terceros países de ejemplares en formato accesible de determinadas obras y otras prestaciones protegidas por derechos de autor y derechos afines en favor de personas ciegas, con discapacidad visual o con otras dificultades para acceder a textos impresos.

El principio básico contenido en el Reglamento es que no se podrán exigir otras condiciones adicionales que las previstas en la Directiva (UE) 2017/1564 para el intercambio interno y, consecuentemente, no está permitida la previa comprobación de disponibilidad comercial, siquiera respecto de las copias accesibles importadas o exportadas fuera del mercado interior ${ }^{37}$.

De esta suerte, con la Directiva y Reglamento de implementación del TM se introduce una herramienta más ${ }^{38}$ que facilita el cumplimiento del objetivo marcado por la Estrategia para el Mercado Único Digital de promover la accesibilidad para los europeos con discapacidad ${ }^{39}$.

La Comisión y los Estados miembros deben garantizar el cumplimiento de la Convención de las Naciones Unidas sobre los derechos de las personas con discapacidad, en particular sus artículos 9 y 21, y, con el fin de fomentar el acceso a la información de las personas con discapacidad intelectual, deben proporcionarse alternativas en un lenguaje fácil de leer en la mayor medida posible de conformidad con el principio de proporcionalidad. Los Estados miembros, mediante la ratificación, y la Unión, mediante la celebración, de la citada Convención, se han comprometido a adoptar medidas adecuadas para asegurar el acceso de las personas con discapacidad, en igualdad de condiciones con los demás, a nuevas tecnologías y sistemas de la información y la comunicación, incluido internet, facilitando el acceso a información de las personas con discapacidad intelectual, ofreciendo alternativas en un lenguaje fácil de leer en la mayor medida posible y de manera proporcionada.

\section{ANTECEDENTES DE LA TRANSPOSICIÓN AL DERECHO ESPAÑOL DE LA DIRECTIVA (UE) 2017/1564: EL PAPEL DE LA ONCE}

Antes de proceder al análisis de la transposición al derecho español de la Directiva (UE) $2017 / 1564$, es preciso señalar que, a diferencia de lo que ocurre con otros temas relativos

36 DOUE de 20 de septiembre de 2017.

37 Puede resultar de interés algunas reflexiones en CASTELLÓ PASTOR, J.J., «Portabilidad transfronteriza de contenidos digitales protegidos por derechos de autor en el Unión Europea», InDret, núm. 1, 2019, pp.1-25, especialmente p.8.

38 Estamos en la misma línea de la Directiva (UE) 2016/2102 del Parlamento Europeo y del Consejo, que obliga a los Estados miembros a garantizar que los sitios web de sus organismos públicos sean accesibles con arreglo a los principios de perceptibilidad, operabilidad, comprensibilidad y solidez y que cumplan los requisitos establecidos en dicha Directiva (DOUE de 2 de diciembre de 2016).

39 Vid. Comunicación de la Comisión al Parlamento Europeo, al Consejo, al Comité Económico y social Europeo y al Comité de las Regiones «Estrategia Europea sobre Discapacidad 2010-2020: un compromiso renovado para una Europa sin barreras». Bruselas, 15.11.2010, $\operatorname{COM}(2010) 636$ final. 
a la propiedad intelectual, España fue pionera en materia de excepciones del derecho de autor en beneficio de personas con discapacidad.

No se puede entender esta afirmación sin tener en cuenta el papel jugado por la ONCE (Organización Nacional de Ciegos de España), entidad sin ánimo de lucro, en la lucha por la inclusión y no discriminación de las personas con discapacidad visual.

En los convulsos tiempos del final de la guerra civil española, el 13 de diciembre de 1938, se constituye la Organización Nacional de Ciegos, que en 1952, añade a su denominación la E de España. Así, la ONCE tuvo como fin social, desde sus comienzos, la integración laboral y social de las personas con discapacidad visual.

Respecto de su naturaleza jurídica es una corporación de derecho público de carácter social, y a los efectos que aquí interesan, destaca su papel en la promoción de la educación de las personas invidentes como herramienta de inclusión social.

Por lo que a su biblioteca se refiere, los lectores con ceguera o discapacidad visual grave disponen de más de 50.000 obras adaptadas para poder descargarse a través de la Biblioteca Digital ONCE (BDO), en la que cerca de la mitad están en formato TLO (para reproductor braille) y las demás en DAISY (Digital Accessible Information System) para reproductor de sonido ${ }^{40}$. Este único dato es suficiente para ilustrar la trascendencia de la entrada en vigor del TM, puesto que los intercambios transfronterizos permitirán a las personas con discapacidad hispanohablantes el acceso a un material que, en muchos casos, la escasez de recursos en sus países no permitiría acceder de otra manera.

La presencia de la ONCE en la sociedad ha permitido que la legislación española haya acogido tempranamente la excepción que autorizaba que dicha organización pudiese adaptar el formato de los libros analógicos para su lectura por las personas ciegas o con dificultades para la lectura.

Para ese desarrollo legislativo, el apoyo constitucional se ubicó en el artículo 49 $\mathrm{CE}$, según el cual «Los poderes públicos realizarán una política de previsión, tratamiento, rehabilitación e integración de los disminuidos físicos, sensoriales y psíquicos a los que prestarán la atención especializada que requieran y los ampararán especialmente para el disfrute de los derechos que este Título otorga a todos los ciudadanos ${ }^{41}$.

Así, en la redacción originaria de la LPI de 1987, las obras ya divulgadas podrían reproducirse sin autorización del autor «para el uso privado de invidentes siempre que la reproducción se efectúe mediante el sistema Braille u otro procedimiento específico y que las copias no sean objeto de utilización lucrativa» (artículo 31.3), por lo tanto se ceñía al derecho de reproducción y a invidentes.

Ese mismo texto pasa al Texto Refundido de la Ley de Propiedad Intelectual (LPI) de $1996^{42}$, pero con la transposición de la Directiva 2001/29/CE, concretamente de su ar-

40 Sirve para la adaptación en audio. DAISY es un estándar abierto que permite configurar una estructura de navegación más amplia, es decir, el usuario puede moverse entre capítulos, subcapítulos, apartados, párrafos o frases; o acceder directamente a una página concreta o un punto de lectura marcado previamente.

41 La Constitución Española es de 1978 y, por lo tanto, el lenguaje no está adaptado a los vigentes parámetros inclusivos.

42 Real Decreto Legislativo 1/1996, por el que se aprueba el Texto Refundido de la Propiedad Intelectual (LPI) y sus posteriores modificaciones. Se puede consultar su versión consolidada en la página web del Boletín Oficial del Estado www.boe.es. 
tículo 5.3.b ${ }^{43}$, un nuevo artículo 31 bis. 2 LPI exceptúa tanto el derecho de reproducción como los de distribución y comunicación pública, cuando tales actos se realicen en beneficio de las personas con discapacidad, siempre que los mismos carezcan de finalidad lucrativa, guarden una relación directa con la discapacidad de que se trate, se lleven a cabo mediante un procedimiento o medio adaptado a la discapacidad y se limiten a lo que ésta exige $^{44}$. En suma, el límite se extiende a cualquier discapacidad y afecta a los derechos de reproducción, distribución y comunicación pública, y se añaden dos condiciones más, presentes en la DDASI: que los actos guarden una relación directa con la discapacidad y se limite a lo que ésta exige.

A pesar de que se haya celebrado por la doctrina ${ }^{45}$ y por los agentes sociales implicados en la eliminación de barreras para el acceso a la cultura por personas con discapacidad, todavía eran muchas las reivindicaciones. En particular, la posibilidad de intercambios, cesiones y préstamos, de materiales adaptados, con vistas a reducir los costes y alcanzar un número más elevado de usuarios.límite se extiende a cualquier discapacidad y afecta a los derechos de reproducción, distribución y comunicación pública. Se exige, como se venía haciendo, que la utilización se lleve a cabo mediante un procedimiento o medio adaptado a la discapacidad y se añaden dos condiciones más previstas en la directiva: que los actos guarden una relación directa con la discapacidad y se limiten a lo que ésta exige.límite se extiende a cualquier discapacidad y afecta a los derechos de reproducción, distribución y comunicación pública. Se exige, como se venía haciendo, que la utilización se lleve a cabo mediante un procedimiento o medio adaptado a la discapacidad y se añaden dos condiciones más previstas en la directiva: que los actos guarden una relación directa con la discapacidad y se limiten a lo que ésta exige. límite se extiende a cualquier discapacidad y afecta a los derechos de reproducción, distribución y comunicación pública. Se exige, como se venía haciendo, que la utilización se lleve a cabo mediante un procedimiento o medio adaptado a la discapacidad y se añaden dos condiciones más previstas en la directiva: que los actos guarden una relación directa con la discapacidad y se limiten a lo que ésta exige. límite se extiende a cualquier discapacidad y afecta a los derechos de reproducción, distribución y comunicación pública. Se exige, como se venía haciendo, que la utilización se lleve a cabo mediante un procedimiento o medio adaptado a la discapacidad y se añaden dos condiciones más previstas en la directiva: que los actos guarden una relación directa con la discapacidad y se limiten a lo que ésta exige.

Ello explica que, con el inicio de los trabajos de preparación del TM, la ONCE, en el marco de la UMC, tuviese un papel activo y destacado en la elaboración del Tratado, y precisamente España, al amparo del trabajo realizado por la ONCE, fuese uno de sus Estados impulsores. Posteriormente, en el proceso de transposición de la Directiva (UE) 2017/1564, la organización sin ánimo de lucro también estuvo presente en las negociaciones para mantener el límite como no remunerado, según la tradición normativa española.

43 La transposición de la DDASI, en particular de su artículo 5.3 b), se hizo por la Ley 23/2006, de 7 de julio, por la que se modifica la LPI (BOE de 8 de julio de 2006).

44 También la Ley 10/2007, de 22 de junio, de la lectura, del libro y de las bibliotecas que en su disposición adicional tercera establece que las Administraciones Públicas promoverán el acceso de las personas con discapacidad, normalizado y sin discriminaciones de este tipo de servicios, bienes y productos culturales.

45 LÓPEZ SÁNCHEZ, C., «La utilización de una obra intelectual», cit., pp. 252 y 253. 


\section{ANÁLISIS CRÍTICO DEL ARTÍCULO 31 TER DE LA LEY DE PROPIEDAD INTELECTUAL}

En la vigente LPI las excepciones a la necesidad de autorización de los titulares de derechos $^{46}$ aparecen enumeradas en los artículos 31 a 40 bis, del Capítulo II del Libro I.

En particular, el artículo 31 ter es el resultado de la transposición de la Directiva (UE) $2017 / 1564{ }^{47}$ y está dedicado a la «Accesibilidad para personas con discapacidad». En un primer apartado describe las características generales de los actos autorizados en beneficio de las personas con discapacidad y en los apartados 2, 3, 4 y 5 trata especialmente de la discapacidad visual y de la dificultad para acceder a obras impresas.

De ese modo, el precepto recoge una excepción a los derechos exclusivos regulados en la LPI de carácter no remunerado y que funciona, a diferencia, por ejemplo de las excepciones del artículo 37 LPI a favor de las bibliotecas, en dos fases. Primero habilita a entidades autorizadas a llevar a cabo actos de reproducción, distribución y comunicación pública de obras y, en un segundo momento, autoriza a los beneficiarios directos, es decir, a las personas con discapacidad, a acceder a los materiales adaptados.

Sobre el carácter no remunerado, el artículo 4.4 TM dispone que corresponderá a la legislación nacional determinar si las limitaciones y excepciones previstas en el presente artículo están sujetas a remuneración. Como se ha anotado anteriormente, la Directiva (UE) 2017/1564 deja a los países miembros la decisión sobre la exigencia o no de remuneración compensatoria. España, a diferencia, por ejemplo, de Holanda, Alemania, Austria, Suecia, sigue con su tradición de límite no remunerado.

Algunos autores manifestaron su desacuerdo, en la redacción anterior a la vigente, por la ausencia de una posible remuneración económica, en vista de que la amplitud de las posibles utilizaciones de la obra, aunque sin finalidad lucrativa, no implica necesariamente la inocuidad absoluta en la explotación habitual de la obra ${ }^{48}$; no obstante, ha prevalecido la consideración humanitaria del precepto y la consecuente función social del derecho contenido en el mismo.

En esa misma línea, de implicación de los autores en las medidas que faciliten el acceso de las personas con discapacidad, incluso para fomentar su acción creadora, no está de menos recordar que, respecto de las entidades de gestión de los derechos de autor, la clara configuración de esa faceta social en el artículo 178 LPI. En efecto, el precepto impone obligaciones como la promoción de actividades o servicios de carácter asistencial en beneficio de sus socios, así como la realización de actividades de formación y promoción de autores y artistas intérpretes o ejecutantes. Y, expresamente, determina que las entidades de gestión de los derechos de autor deben fomentar la oferta digital legal de obras y prestaciones protegidas cuyos derechos gestionan, y, también, fomentar la integración de autores y artistas con discapacidad en su respectivo ámbito artístico, o ambos, del mis-

46 Como señala MARTÍN SALAMANCA, «Derecho de autor», cit.,, p.99, «titulares de los derechos exclusivos lo serán, tanto los de carácter originario (es decir, los que adquieren esta condición por realizar el acto de creación), como los de carácter derivativo (esto es, aquellos a quienes los titulares originarios hubieran transmitido su derecho exclusivo, bien mediante un negocio «inter vivos»-cesión-, bien con carácter «mortis causa»)».

47 Transposición llevada a cabo por la Ley 2/2019, de 1 de marzo que modifica la LPI (procedente del Real Decreto Ley 2/2018, de 13 de abril).

48 MARTÍN SALAMANCA, S., «Artículo 31 bis», cit., p. 251. 
mo modo que la promoción de la oferta digital de sus obras, creaciones y prestaciones, y el acceso de las personas discapacitadas a las mismas en el ámbito digital.

Y respecto de los editores, también se puede hablar de una tradición de solidaridad. La propia ONCE reconoce la colaboración de las editoriales para facilitar una mayor rapidez en el proceso de adaptación de textos es muy importante, sobre todo, cuando se trata de textos educativos que tienen que estar a punto cuando dan comienzo las clases en cada curso académico, y son muchos los acuerdos de colaboración con esa entidad que permiten que se pueda disponer de los textos digitalizados, agilizando sensiblemente el proceso de adaptación.

\subsection{Elemento subjetivo: entidades autorizadas y beneficiarios}

En este apartado es preciso tener en cuenta tanto aquellas entidades autorizadas a llevar a cabo los actos relativos a los derechos exclusivos del autor como los beneficiarios finales del límite.

Para el artículo 31 ter. 1) no necesitan autorización del titular de los derechos de propiedad intelectual los actos de reproducción, distribución y comunicación pública de obras ya divulgadas que se realicen en beneficio de personas con discapacidad, siempre que los mismos carezcan de finalidad lucrativa, guarden una relación directa con la discapacidad de que se trate, se lleven a cabo mediante un procedimiento o medio adaptado a la discapacidad y se limiten a lo que esta exige.

Tales actos serán realizados por las entidades autorizadas.

Recordemos que en el TM, la dinámica del límite a favor de las personas con discapacidad está construida sobre la base de la figura del «tercero de confianza», aquellas personas o entidades específicamente autorizadas por el gobierno nacional, dedicados a producir obras en formatos accesibles para servicio y beneficio de las personas con discapacidad visuales.

El acceso de los beneficiarios al límite descrito no se puede hacer directamente, sino que es preciso el tratamiento previo del texto por entidades. En la senda marcada por la Directiva (UE) 2017/1564, el apartado 2 del artículo 31 ter considera que serán entidades autorizadas, a los efectos de este artículo, aquellas entidades que proporcionen sin ánimo de lucro a las personas ciegas, con discapacidad visual o con otras dificultades para acceder a textos impresos, educación, formación pedagógica, lectura adaptada o acceso a la información, o que, siendo instituciones públicas u organizaciones sin ánimo de lucro, tengan estos servicios como una de sus actividades principales, como una de sus obligaciones institucionales o como parte de sus misiones de interés público ${ }^{49}$.

Ahora bien, hasta aquí, las entidades autorizadas, pero los auténticos beneficiarios del límite son las personas con discapacidad.

En los términos del párrafo segundo artículo 31 ter LPI se entiende por discapacidad visual y dificultad para acceder a obras impresas, incluido el formato audio y los formatos digitales, a los efectos de determinar los beneficiarios de este apartado, las que tienen las personas que ${ }^{50}$ :

49 Como se pudo apuntar, ese papel es desempeñado principalmente, aunque no exclusivamente, por la ONCE.

50 La nota descriptiva de la OMS núm.282 (2014) se refiere a cuatro niveles de capacidad de visión: visión normal, discapacidad visual moderada, discapacidad visual grave y la ceguera. Asume, asimismo, la Clasificación 
a. sean ciegas;

b. tengan una discapacidad visual que no pueda corregirse para darle una función visual sustancialmente equivalente a la de una persona sin ese tipo de discapacidad, y que, en consecuencia, no sean capaces de leer obras impresas en una medida sustancialmente equivalente a la de una persona sin ese tipo de discapacidad;

c. tengan una dificultad para percibir o leer que, en consecuencia, las incapacite para leer obras impresas en una medida sustancialmente equivalente a la de una persona sin esa dificultad;

d. o no puedan, debido a una discapacidad física, sostener o manipular un libro o centrar la vista o mover los ojos en la medida que normalmente sería aceptable para la lectura.

\subsection{Elemento objetivo: la obra accesible}

La accesibilidad es una condición previa a la participación en la sociedad y en la economía, y la UE tiene un largo camino que recorrer para conseguirla. Por «accesibilidad» se entiende el acceso de las personas con discapacidad, en las mismas condiciones que el resto de la población, al entorno físico, al transporte, a las tecnologías y los sistemas de la información y las comunicaciones (TIC), y a otras instalaciones y servicios ${ }^{51}$. En esencia hablamos de audio (voz sintética o voz humana), de Braille o de macrotipos, considerando que en los últimos años, las tecnologías de la información han abierto un amplio abanico de posibilidades ${ }^{52}$.

Por lo tanto, la cuestión no es la creación de contenidos, sino de la accesibilidad de obras o prestaciones ya divulgadas y protegidas por el derecho de autor no accesibles a personas con discapacidad visual o cualquier otra dificultad de lectura.

En los términos del artículo 10.1 TLPI, son objeto de propiedad intelectual todas las creaciones originales literarias, artísticas o científicas expresadas por cualquier medio o soporte, tangible o intangible, actualmente conocido o que se invente en el futuro.

El límite o excepción aquí tratado afecta, según el contenido del artículo 31 ter, a las obras ya divulgadas, en atención al derecho moral de inédito de la obra (artículo 14 LPI). En ese sentido, el artículo 4 LPI entiende por divulgación de una obra toda expresión de la misma que, con el consentimiento del autor, la haga accesible por primera vez al público en cualquier forma. Otro fundamento para la exigencia de la divulgación se encuentra en la propia esencia del límite, es decir, en el acceso a la cultura en condiciones de igualdad.

Internacional de Enfermedades 11 (2018) que clasifica la deficiencia visual en dos grupos: de lejos y de cerca. Para la deficiencia de la visión de lejos se entiende: - leve: agudeza visual inferior a 6/12; - moderada: agudeza visual inferior a 6/18; - grave: agudeza visual inferior a 6/60; - ceguera: agudeza visual inferior a 3/60. Por otra parte, para la deficiencia de la visión de cerca, agudeza visual inferior a N6 o N8 a $40 \mathrm{~cm}$ con la corrección existente Vid. https://www.who.int/es/news-room/fact-sheets/detail/blindness-and-visual-impairment

51 COMISIÓN EUROPEA, COM(2010) 636 final.

52 . A modo de ejemplo, Museos como El Prado han incorporado soluciones de accesibilidad para personas con discapacidad visual, mediante una tecnología 3D llamada 'Didu', para facilitar que las obras tengan relieve y se puedan tocar con las manos. En todo caso, el departamento de Tecnología Accesible e I+D de Fundación ONCE está haciendo una apuesta por la inteligencia artificial y la robótica. 
La exigencia de que la obra esté divulgada se entiende porque si de lo que se trata es de que la persona con discapacidad pueda acceder a las obras en las mismas condiciones que el público en general, no tendría sentido permitirle el acceso a creaciones que no están a disposición de ese público, debido a su condición de inéditas ${ }^{53}$.

El TM se refiere a obras literarias o artísticas en forma de texto, notación y/o ilustraciones conexas con independencia de que hayan sido publicadas o puestas a disposición del público por cualquier medio. Puede ser un libro, una partitura, una revista, un periódico. La Directiva (UE) 2017/1564 extiende la excepción a las prestaciones, es decir, aquellas prestaciones que corresponden a titulares de otros derechos de propiedad intelectual (derechos conexos o afines).

\subsection{Usos autorizados}

El artículo 31 ter se refiere a actos de reproducción, distribución y comunicación pública de obras ya divulgadas que se realicen en beneficio de personas con discapacidad.

Así, en aquellos supuestos especiales que no entren en conflicto con la explotación normal de la obra, y que no perjudiquen en exceso los intereses legítimos del titular del derecho, las entidades autorizadas establecidas en España que produzcan ejemplares en formato accesible de obras para uso exclusivo de personas ciegas, con discapacidad visual o con otras dificultades para acceder a textos impresos, podrán llevar a cabo, en los términos del artículo 31 ter LPI, los actos del apartado anterior, de la forma referida en el mismo, para uso exclusivo de dichos beneficiarios o de una entidad autorizada establecida en cualquier Estado miembro de la Unión Europea. Asimismo, los beneficiarios y las entidades autorizadas establecidas en España podrán conseguir o consultar un ejemplar en formato accesible facilitado por una entidad autorizada establecida en cualquier Estado miembro de la Unión Europea.

Llama la atención que no exista una referencia expresa a uno de los derechos de explotación, el derecho de transformación de la obra (artículo 21 LPI) ${ }^{54}$. Ello porque muchas de las acciones aquí descritas y que tienen por fin hacer la creación accesible al público con una discapacidad visual requieren una actividad manipuladora previa que podría ser vista como una transformación ${ }^{55}$.

Incluso compartiendo muchas de las dudas suscitadas sobre las fronteras entre reproducción u transformación, disquisiciones aparte, entiendo que el fundamento del límite y su configuración permite incluir, en todo caso, las adaptaciones aquí mencionadas dentro del campo objetivo de actuación del límite, porque no se obtiene, como exige el artículo 21 LPI, una obra diferente.

A favor de esta postura, no está de menos recordar que la adaptación de un texto al sistema Braille no se considera una traducción -ésta sí una modalidad de transformación-, sino una reproducción en un código distinto ${ }^{56}$. A diferencia de un traductor que ejerce una

53 LÓPEZ SANCHEZ, C., «La utilización de una obra intelectual», cit., p. 260 y LÓPEZ MAZA, S., «Comentario al artículo 31 bis», cit., p. 614.

54 Sobre el tema del derecho de transformación LÓPEZ SANCHEZ, C., «La utilización de una obra intelectual», cit., pp. 262-265.

55 MARTÍN SALAMANCA,S., «Derecho de autor», cit., p. 107.

56 Por todos LÓPEZ MAZA, S., «Comentario al artículo 31 bis», cit., p. 612. 
actividad creativa sobre el texto, las adaptaciones para la accesibilidad son consideradas actividades carentes de originalidad, en el sentido de la $\mathrm{LPI}^{57}$.

En todo caso, de lo que se trata es de eliminar barreras de acceso. No es sin más el acceso, sino el acceso a un formato adaptado a las necesidades de una persona con discapacidad visual o cualquier otra que le impida la lectura y el acceso a los contenidos.

Siguiendo los ejemplos proporcionados por la UMC, las actividades autorizadas serían, por ejemplo, la conversión de copias de formatos convencionales a formatos accesibles y la simple reproducción de copias en formatos accesibles, como en el caso de la creación de libros hablados a partir de un libro convencional o las copias de un libro en Braille. Así, los libros DAISY solo audio (Sistema de Información Digital Accesible), libros de texto íntegro DAISY (texto destacado sincronizado con conversión de texto en habla o con voz humana), EPUB3 (formato de libro digital con características de accesibilidad incorporadas y LFK (de uso habitual en los países de lengua rusa).

Sobre todos esos sistemas, no hay que olvidar que los titulares de derechos de propiedad intelectual no podrán utilizar medidas tecnológicas que impliquen la inaplicación de la excepción ${ }^{58}$

Ahora bien, no entran en los usos autorizados por el límite del artículo 31 ter LPI la utilización terapéutica de contenidos protegidos por el derecho de autor ${ }^{59}$. Lo que se autoriza son los usos necesarios para la accesibilidad de la obra, no su utilización en terapias u otros procesos de naturaleza médica. Siquiera una interpretación extensiva de la regla de los tres pasos podría amparar ese nivel de ampliación de un límite. Ese criterio se puso de manifiesto en la Sentencia del Tribunal de Justicia de la Unión Europea de 27 de febrero de 2014 (Sala Cuarta ${ }^{60}$. En ella se discutía si entraba dentro del límite a favor de las personas con discapacidad descrito en el artículo 5.3.b) DDASI la utilización de contenidos protegidos por un establecimiento termal, por medio de aparatos de televisión o aparatos de radio instalados en sus habitaciones, con el argumento de que la música y otros contenidos audiovisuales son fundamentales para la mejora de la condición física y

57 Como explica la ONCE en su web, Para la adaptación en braille, lo primero que se hace es digitalizar el texto, para después pasarle un editor braille, llamado Ebrai, que generará un fichero que permitirá su impresión posterior, en una impresora especialmente diseñada para producir braille. Este editor es propiedad de la ONCE, pero está a disposición gratuita de cualquier persona del mundo que lo solicite en la página Web del CTI»

58 Cfr. artículo 197.1b) LPI.

59 LÓPEZ MAZA, S., «Comentario al artículo 31 bis», cit., p. 616 y LÓPEZ SANCHEZ, C., «La utilización de una obra intelectual», cit., p. 266.

60 Caso OSA asunto C-351/12. ECLI:EU:C:2014:110 (TJCE 2014\83). Su apartado 40 deja claro que «el artículo 5, apartado 5, de la Directiva 2001/29 no prevé excepciones o limitaciones de los derechos enunciados en particular en el artículo 3, apartado 1, de dicha Directiva que los Estados miembros puedan establecer, sino que se limita a precisar el alcance de las excepciones o limitaciones previstas en los apartados precedentes de esa última disposición».

En resumen, mantiene que el concepto de «comunicación al público» previsto en la DDASI es interpretado en sentido amplio, de tal manera que la comunicación de obras protegidas en un establecimiento termal mediante la distribución deliberada de una señal a través de receptores de televisión o de radio en las habitaciones de los pacientes, constituye una comunicación al público de acuerdo con el artículo 3 DDASI.

Vid. también sobre los televisores en las habitaciones de un centro hospitalario las SSAP de Madrid de 14 de septiembre de 2018 (AC 2018\1782), 29 de noviembre de 2013 (JUR 2014\9001), 15 de junio de 2012 (AC 2012\1335) y 16 de enero de 2012 (JUR 2012\66581), SAP de Alicante de 30 de mayo de 2013 (JUR 2013\266374) y SAP Almería de 4 de noviembre de 2014 (JUR 2015\83379). En particular, la SAP de Madrid de 27 de marzo de 2015 (AC 2015\1185) rechaza frontalmente la equiparación entre personas enfermas o lesionadas con las personas discapacitadas. 
mental de sus clientes, que en su mayoría tienen discapacidades de diferentes alcances, postura rechazada por el Tribunal.

Para resumir, y acudiendo al Considerando 9 de la Directiva (UE) 2017/1564, los usos permitidos deben incluir la producción de ejemplares en formato accesible, tanto por parte de los beneficiarios como de las entidades autorizadas dedicadas a atender sus necesidades, ya sean estas organizaciones públicas o privadas, en particular bibliotecas, centros educativos y otras organizaciones sin ánimo de lucro, que se dediquen a atender a personas con dificultades para acceder a textos impresos como una de sus actividades principales, como una de sus obligaciones institucionales o como parte de sus misiones de interés público. Los usos permitidos en la presente Directiva también deben incluir la producción de ejemplares en un formato accesible, para uso exclusivo de los beneficiarios, por parte de una persona física que actúe en nombre de un beneficiario o que ayude al beneficiario que produce dichos ejemplares. Solo deben producirse ejemplares en formato accesible de aquellas obras u otras prestaciones a las que los beneficiarios o las entidades autorizadas tengan lícitamente acceso. Los Estados miembros deben velar por que ninguna cláusula contractual destinada a impedir o limitar de cualquier modo la aplicación de la excepción produzca efectos jurídicos.

\subsection{Obligaciones de las entidades autorizadas}

Las obligaciones de las entidades autorizadas están detalladas en el artículo 31 ter.3 LPI. Así, con el fin de mejorar la disponibilidad de ejemplares en formato accesible y de evitar la difusión no autorizada de obras u otras prestaciones, las entidades autorizadas que participen en la distribución, comunicación al público o puesta a disposición del público de ejemplares en formato accesible deben:

a. Distribuir, comunicar o poner a disposición ejemplares en formato accesible de obras para uso exclusivo de los beneficiarios del apartado anterior o de otras entidades autorizadas.

b. Tomar las medidas necesarias para desincentivar la reproducción, distribución, comunicación al público o puesta a disposición del público, de forma no autorizada, de ejemplares en formato accesible.

c. Gestionar con la diligencia debida las obras, así como sus ejemplares, en formato accesible, y mantener un registro de dicha gestión.

d. Publicar información sobre las actuaciones realizadas en aplicación de las letras anteriores, siendo suficiente, a estos efectos, una actualización semestral en su portal de internet y una remisión de dicha información, actualizada semestralmente, al centro directivo del Ministerio de Cultura y Deporte competente en materia de propiedad intelectual y a la entidad o entidades de gestión de derechos de propiedad intelectual que representen a los titulares de las obras adaptadas a formato accesible. El referido centro directivo del Ministerio de Cultura y Deporte creará y llevará un registro de las entidades autorizadas y podrá comprobar, en cualquier momento, las actuaciones informadas por estas. 
e. Facilitar de forma accesible, previa solicitud, la lista de obras y formatos disponibles según lo previsto en la anterior letra d), y los datos de las entidades autorizadas con las que hayan intercambiado ejemplares en formato accesible, a los beneficiarios del apartado anterior, a otras entidades autorizadas o a los titulares de derechos.

El legislador establece un control continuo de la actividad de las entidades autorizadas de modo que se garantice la utilización correcta del límite, por ello, el párrafo 4 del artículo 31 ter LPI impone la obligación de comunicar al centro directivo del Ministerio de Cultura y Deporte competente en materia de propiedad intelectual, el cumplimiento de los requisitos contenidos en los anteriores apartados 2 y 3 , exigibles a una entidad autorizada. En caso de incumplimiento de los mismos y de no ser atendido el oportuno requerimiento de subsanación, se requerirá a aquellas el cese de la actividad regulada en el presente artículo.

De esa manera, con el cumplimiento de las obligaciones previstas es más fácil asegurar la aplicación del límite o excepción del artículo 31 ter de forma que no cause un perjuicio injustificado a los intereses legítimos del autor o que vayan en detrimento de la explotación normal de las obras a que se refiera

Por último, el apartado 5 del artículo 31 ter recuerda que la regulación actual del tema se establece sin perjuicio de la aplicabilidad de la normativa de la Unión Europea en materia de intercambio transfronterizo entre esta y terceros países de ejemplares en formato accesible de determinadas obras y otras prestaciones protegidas por derechos de autor y derechos afines en favor de personas ciegas, con discapacidad visual o con otras dificultades para acceder a textos impresos.

\section{CONCLUSIONES}

En el ámbito comunitario, la implementación del TM tuvo lugar por medio de la Directiva (UE) 2017/1564 que recogió un límite, a diferencia de otros regulados en la DDASI, de regulación obligatoria -no facultativa- para todos los Estados miembros.

La transposición al derecho español dio como resultado la actual redacción del artículo 31 ter LPI que recoge un límite o excepción al derecho de propiedad intelectual en favor de personas ciegas, con discapacidad visual o con otras dificultades para acceder a textos impresos.

De esa manera, se sigue con la tradición de regular un límite no remunerado que, en consonancia con la función social del derecho de autor, permite el acceso a las obras en condiciones de igualdad con aquellos usuarios sin discapacidad o dificultades para la lectura. En ese sentido, el límite se centra fundamentalmente en la discapacidad visual u otras circunstancias que dificulten la lectura, posibilitando la reproducción, distribución y comunicación pública, sin necesidad de autorización, de obras ya divulgadas, cuando tales actos se realicen en beneficio de personas con discapacidad.

Una particularidad de este límite, respecto a otros tipos de excepción a los derechos de propiedad intelectual, es que la autorización para los actos de reproducción, distribución y comunicación pública va dirigida a un sujeto intermediario necesario para que el beneficiario final del límite -la persona con discapacidad- pueda acceder a la obra. Ese 
tercero de confianza son las entidades autorizadas establecidas en España que produzcan ejemplares en formato accesible de obras para uso exclusivo de personas ciegas, con discapacidad visual o con otras dificultades para acceder a textos impresos, particularmente, la ONCE.

En todo caso, la entidad autorizada debe llevar a cabo los actos amparados por el precepto con la suficiente diligencia, a los efectos de evitar perjuicios innecesarios a los legítimos intereses de los titulares de derechos de propiedad intelectual. Asimismo, y aquí está una de las facetas del gran impulso del TM al objetivo de acceso universal a la cultura y a la educación, las obligaciones de comunicación y registro impuestas a las entidades autorizadas van en la línea de ampliar el acervo de materiales disponibles, cuestión de vital importancia si tenemos presente el potencial aumento de los intercambios transfronterizos que favorecerán que un mayor número de personas con discapacidad tengan acceso a las obras.

En relación con este último aspecto, una de las ideas presentes en este trabajo y que ahora se reitera, es que la propiedad intelectual es una herramienta más para el objetivo último de integración y desarrollo de la personalidad de las personas con discapacidad. El artículo 31 ter LPI debe ser interpretado, desde esa perspectiva, como una norma inserta en un marco general de medidas de estímulo al acceso universal a la educación y a la cultura y que sirven de fomento de la creatividad.

Por ello, y a modo de cierre, se insiste en que las respuestas que proporciona el régimen de la propiedad intelectual a los problemas de acceso universal no están exclusivamente en la regulación de un límite a los derechos de autor y conexos sino también en la inclusión de criterios de acceso universal en el diseño y creación de contenidos para que sean inicialmente accesibles a cualquier usuario. De ese modo, las personas con discapacidad podrán desarrollar en igualdad de condiciones tanto su derecho de acceso a la educación y a la cultura como su derecho a la producción y creación literaria, artística, científica y técnica, reconocido en el artículo 20.1. b) CE.

\section{BIBLIOGRAFÍA}

Anguita Villanueva, L. «Derechos fundamentales y propiedad intelectual: el acceso a la cultura», en Propiedad Intelectual, Derechos Fundamentales y Propiedad Industrial (coord. César Iglesias Rebollo), Reus, Madrid, 2005, pp. 49-87.

CARON, C. «Les exceptions au regard du fondement du droit d'auteur en droit français», Les exceptions au Droit D'Auteur. État des lieux et perspectives dans l'Union européenne (dirs. André Lucas, Pierre Sirinelli, Alexandra Bensamoun), Dalloz, París, 2012, pp. 19-25.

Castelló Pastor, J. J. «Comentario al artículo 31 bis», en Comentarios a la Ley de Propiedad Intelectual (dirs. Felipe Palau Ramírez y Guillermo Palao Moreno), Tirant lo Blanch, Valencia, 2017, pp. 516-520.

«Portabilidad transfronteriza de contenidos digitales protegidos por derechos de autor en la Unión Europea», en InDret, núm. 1, 2019, pp. 1-25.

EIFL. Guía EIFL (Electronic Information for Libraries) para bibliotecas. El Tratado de Marrakech para facilitar el acceso a las obras publicadas para las personas ciegas, con discapacidad visual, o con otras dificultades para acceder al texto impreso, 2015. Disponible en https://www.eifl.net/system/ files/resources/201710/marrakesh_sp_v2_low.pdf

GEIGER, C. Droit d'auteur et droit du public à l'information: approche de droit comparé, Litec, París, 2004. 
Helfer, L. R., Land, M. K., Okedisi, R. L. y Reichman, J. H. Guía del Tratado de Marrakech de la Unión Mundial de Ciegos, 2016. Disponible en http:/www.worldblindunion.org/Spanish/Our-work/ our-priorities/Pages/La-Guía-de-la-Unión-Mundial-de-Ciegos-al-Tratado-de-Marrakech.aspx

IFLA. Implementar el Tratado de Marrakech para personas con dificultades para acceder al texto impreso de acuerdo con la legislación española. Disponible en https://www.ifla.org/files/assets/hq/ topics/exceptions-limitations/ponerse_en_marcha_ley_espanola.pdf

López MazA, S. «Comentario al artículo 31 bis», en Comentarios a la Ley de Propiedad Intelectual (dir. Rodrigo Bercovitz), Tecnos, Madrid, 2017, pp. 609-620.

LóPEZ SÁNCHEZ, C. «La utilización de una obra intelectual a favor de personas con discapacidad», en Límites a la propiedad intelectual y nuevas tecnologías (coord. Juan Antonio Moreno Martínez), Dykinson, Madrid, 2008, pp. 239-283.

Martín Salamanca, S. «Artículo 31 bis», en Comentarios a la Ley de Propiedad Intelectual (dir. José Miguel Rodríguez Tapia), Thomson Reuters-Civitas, Cizur Menor (Navarra), 2007, pp. 246-251.

«Derecho de autor», en Derecho de la propiedad intelectual: derecho de autor y propiedad industrial (dir. Miguel Ruiz Muñoz), Tirant lo Blanch, Valencia, 2017.

OMPI. El Tratado de Marrakech - Hacia la erradicación del hambre mundial de libros, Ginebra, 2016.

SERrANo Fernández, M. «Acceso a la cultura y propiedad intelectual. El derecho de acceso a la cultura: su significado constitucional. La función social de la propiedad intelectual: la tutela del derecho de acceso a la cultura del art. 40 TRLPI», en Constitución y Propiedad Intelectual (coord. Luis Anguita Villanueva), Reus, Madrid, 2014, pp. 119-140.

VIVAs Tesón, I. «El ejercicio de los derechos de la personalidad de la persona con discapacidad», en Claves para la adaptación del Ordenamiento jurídico privado a la Convención de Naciones Unidas en

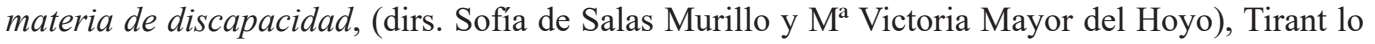
Blanch, Valencia, 2019, pp. 409-443.

XAlABARDER, R. «Implementación del Tratado de Marrakech para facilitar el acceso a obras protegidas por personas con discapacidad visual. Crónica de legislación, en Ars Iuris Salmanticensis, vol. 6, junio 2018, pp. 254-259. 